\title{
Managing technology portals: using the Web to find and transfer technologies
}

\author{
David Raitt \\ Technology Transfer Programme \\ European Space Agency - ESTEC \\ david.raitt@esa.int
}

\section{Contents}

1. Introduction

2. European Space Agency (ESA) Technology Transfer Programme

3. Technology transfer and exchange Web sites

4. Conclusion

5. References

\section{Introduction}

Every year billions of dollars are spent by companies, research organizations and academic institutes for research and development activities in virtually every technological sector. Unfortunately, most of the results achieved from such research activities are a long way from commercialization with respect to their overall potential. Furthermore, many companies, particularly in Europe where there is a large number of small and medium-sized enterprises (SMEs), lack the necessary resources for product development. Equally, universities, which are viewed as the major source of innovative research, often lack the means to bring the fruits of their efforts to the marketplace themselves.

Cooperation between academic institutes and industry is no easy matter at the best of times, even when there is awareness on both sides of the benefits to be gained from interaction and a desire to collaborate. Various obstacles can impede academic and industrial cooperation and the subsequent moving of academic research on to the marketplace. These include different perceptions of confidentiality, different motives and ideas regarding collaboration, diverse management styles and working conditions, and so on. These difficulties are compounded when technologies and expertise deriving from high tech sectors such as space research are concerned, since their adaptation needs further work to address the industrial requirements in terms of performance, reliability and costs. However, organizations now realize that it is becoming increasingly necessary to exchange, transfer and license the technologies (including software) and knowledge they have developed in order to access new markets and revenue streams. On the other hand, it is becoming ever more apparent that companies need to acquire new technologies in order to develop their ideas and create new products. 
Technology transfer is the process of utilizing technology, expertise, know-how or facilities for a purpose not originally intended by the developing organization. Technology transfer therefore implies that a technology developed for one sector is now used in a totally different area. For instance, carbon composites developed for the extreme temperatures inside rocket nozzles have been applied as brake pads for aircraft and Formula 1 racing cars; digital signal processing techniques are finding an application in detecting leaks in water pipes; software for damping vibrations during the launch of spacecraft is being used to damp vibrations in concrete mixers; and a new filtration system for recycling the waste water of astronauts is being used by a spring water bottling company. Technology transfer often results in the commercialization of products through licensing or product/process improvement - though this usually takes a couple of years. This article is a discussion of how the Web has been applied already to support or enhance the transfer of technology from one organization (who has been involved in developing a particular technology) to another (who might be interested in the results of applying that specific technology).

\section{ESA Technology Transfer Programme}

By way of example, the Technology Transfer Programme (TTP) of the European Space Agency (ESA) (European Space Agency 2002) was investigated. In the framework of its research and development activities, ESA spends some 150 MEuro each year and, recognizing the enormous potential of the know-how developed within its research and development activities, set up a Technology Transfer Programme over ten years ago. The technology transfer and commercialization program of the USA's NASA goes back much further. In the case of ESA - and this can obviously be extrapolated to other organizations, including universities - such a programme:

- eases the burden imposed on public resources by research and development by adapting space technologies, systems and know-how to other non-space users and applications;

- maximizes the return on investment in space research conducted by ESA for the benefit of its member states;

- minimizes the duplication of research between the space and non-space sectors;

- provides opportunities for researchers to collaborate with other organizations; and

- has the possibility of two-way transfer - both in spin-off from space to non-space sectors and spin-in of technologies developed in non-space sectors which might be relevant to space.

Over the past 12 years, ESA's TTP has achieved remarkable results (European Space Agency 2002), namely:

- more than 150 successful transfers of space technologies;

- over 150 million Euros received by companies making the technologies available;

- six new companies established as a direct result of exploiting technologies;

- nearly 2500 jobs created or saved in Europe; and

- a portfolio of over 450 space technologies available for transfer and licensing.

Organizations in the technology transfer business want to improve services to clients and assist them to transfer and commercialize the advanced technologies they have developed. And what better way to do this today than with the Internet or World-Wide Web? At a minimum, Web sites dealing with technology transfer and exchange need to have a variety of features. They must: 
- provide details on the technologies available for licensing or purchase;

- suggest potential markets for the technologies;

- describe the novelty and benefits of the technology;

- detail who owns the associated intellectual property rights (IPR);

- permit users to search a database for possible technologies; and

- permit users to add their own exploitable technologies to the database.

Some sites offer additional services such as consultancy, technology assessment and training in licensing and IPR.

Within this context, ESA is supporting three complementary Web sites in an attempt to overcome some of the problems previously mentioned. The advantage is that a more direct and targeted approach to the technology donors and receivers is possible. The three Web portals act in close synergy, each of them having complementary roles within the TTP. ESA's own technology portal (see paragraph 3.3) aims at giving an overall view of ESA's activities related to technology transfer, including its major technology brokers and success stories. The Virtual Market Place portal (see paragraph 3.13) is heavily involved in promoting the ESA technology portfolio on the Web, while the T4Techonline portal (paragraph 3.7) offers free consultancy, provided by ESA experts, on new and innovative technologies. This last topic, apart from strengthening the TTP actions, also permits the transfer of knowledge related to space research activities as experts are virtually linked to users through the Web site so that they can interact directly.

\section{Technology transfer and exchange Web sites}

A brief outline of the ESA-supported Web sites is given below. ESA is, however, just one of several organizations involved in providing a Web-based service for technology transfer and exchange and therefore information on some of the other available sites are also provided. The various sites are discussed in alphabetical order. Details of other sites can be found at

http://www.links2go.com/topic/University_Technical_Transfer.

In addition, academic institutions that offer technology transfer services and have Web sites can be found at

http://www.links2go.com/topic/Technical_Transfer.

\subsection{CERN Industry and Technology Liaison Office}

The CERN Industry and Technology Liaison Office (ITLO) was founded in 1987 to stimulate interaction with industry and to assist in issues related to CERN's intellectual property (Technology Transfer 2002). It acts as a unique point of contact for industry for all aspects not directly related to procurement (e.g. general information, collaboration opportunities, technology transfer policy, specific on-site visits and briefings for companies). It strengthens contacts on industrial matters with CERN member states' delegates and industrial liaison officers, as well as external bodies including commercial attachés, chambers of commerce, regional bodies, industrial parks, etc. The ITLO also promotes and assists technology transfer by all relevant means and ensures that CERN's intellectual property rights are adequately protected and correctly applied.

The CERN Technology Database contains information on technology developed and in use at CERN and is compiled and maintained by the ITLO in collaboration with the relevant 
CERN divisions and groups. It makes this information available to industry in CERN's member states, 'as is' or via a licence agreement, and disseminates it within CERN and its collaborating institutes. The database also serves as a point of contact for the flow of technology information to and from CERN; it gathers information on CERN technology directly from sources within CERN and channels enquiries on CERN's technology from member states, collaborating institutes and from CERN itself to the appropriate sources of information. These enquiries include requests for details of technologies as well as information on consultation services.

\subsection{Defense TechLink}

Defense TechLink develops strategic partnerships between the US Department of Defense (DoD) laboratories and companies that utilize aerospace, electronic and other technologies (including agriculture and biotechnology) in the American Northwest (Defense TechLink, n.d.). Partnering with DoD leverages a company's research and development investments and enhances commercialization opportunities. Partnering also helps to identify technologies in companies that meet DoD's research mission. Defense TechLink, operated by Montana State University Tech Link, is sponsored by DoD to facilitate these partnerships at no cost to clients.

Entering into a partnership with Department of Defense Laboratories offers certain advantages:

- Technologies developed for DoD often have commercial application and Defense TechLink will identify these opportunities and facilitate the evaluation and patent licensing process.

- Defense TechLink links companies with expertise in the DoD laboratories to enhance their research and development efforts and potentially lead to DoD purchase of products once they become commercialised.

- In common with other similar services, Defense TechLink can facilitate finding and securing the use of specialized DoD research equipment that may be available and fit a research and development need.

\subsection{ESA TTP Portal}

The objective of this site is to provide information on the ESA TTP, including a description of its SpaceLink network (a network of technology brokers in the ESA member states who carry out the transfer activities on behalf of ESA), details on new and interesting stories of successful space technology transfer, a catalogue of the technologies available for transfer, and other news and resources (European Space Agency 2002). The Web site is basically an informative site and is not really actively involved in the transfer and exchange of technologies as are other sites.

\subsection{National Technology Transfer Centre}

The National Technology Transfer Centre (NTTC) helps to strengthen US industrial competitiveness by promoting the efficient identification, management, development and commercialization of marketable research and technologies (Wheeling Jesuit University). NTTC identifies and markets federal, university and corporate funded technology-based research with commercial potential. It also aggressively pursues partners in the private sector to directly commercialize the technology or further develop the technology into a product with commercial potential. Among the services offered by the NTTC are the Portfolio Inventory which provides clients with a clearer picture of their intellectual property holdings; the Technology Review which assists clients in making early commercialization decisions; 
and the Opportunity Assessment which analyses the competitive position of intellectual property from a technical and market perspective.

Founded in 1989, the NTTC claims to be the undisputed industry leader in the technology transfer and commercialization industry in the USA. Guided by its vision to aid economic development through the mapping of technologies needed to technologies available, NTTC offers a complete portfolio of products and services that enable American businesses to find technologies, facilities and world-class researchers within the federal laboratories and agencies with which they can partner. The core capabilities of NTTC are significantly enhanced by the NTTC Washington Operations office, which supports the Ballistic Missile Defense Organization's technology transfer programme, and by the affiliation with Wheeling Jesuit University and the Center for Educational Technologies.

\subsection{NASA Commercial Technology Network}

One of the better technology Web portals is provided by the NASA Commercial Technology Network (NCTN) which allows users to explore several unique resources to discover NASAsponsored research, technology, technical expertise and research and development capabilities that match the needs and interests of enterprises (United States of America, NASA). The NCTN encompasses over 20 Web sites operated by NASA's national network of programmes, centres and offices sponsored by, and affiliated with, the Commercial Technology Division at NASA Headquarters. These include the Commercial Technology offices at the ten NASA field centres, the NASA Regional Technology Transfer Centers (RTTCs), the National Technology Transfer Center, NASA Tech Briefs, Cosmic, Unisphere, and other specialized organizations and services dedicated to fostering dual-use technology partnerships, and the transfer and commercialization of NASA-sponsored research and technology.

NCTN provides access to a wide array of information resources that can be searched and consulted for research and technology, patents, technical expertise, and research and development facilities as well as for technology partnering, licensing and commercialization opportunities. In addition to serving as an integrated information resource, the NCTN is developing into an electronic marketplace for NASA-sponsored technology, facilitating communications, transactions and partnerships between NASA and the US private sector.

The Network is backed up by a number of publications, databases and archives, including NASA TechBriefs, the monthly digest of NASA technology available for transfer, licensing and commercialization. The related Web site can be browsed for NASA patents and detailed NASA Technical Support Packages for technologies featured in NASA TechBriefs can be downloaded. In addition, the Spinoff database can be browsed or searched to find successful commercial and industrial product applications and processes derived from NASA technology since 1976. Another Web-based service is NASATechTracS, which provides access to NASA's technology inventory together with numerous examples of the successful transfer and commercialization of NASA-sponsored technology.

\subsection{Sibexlink technology exchange}

Established in 1996 as a self-funding organization, Sibexlink aims to promote trade, investment and technology exchange among G-15 and South-South countries and to generate revenue through marketable product services (Sibexlink). It is doing this through its Technology Exchange, which offers a new value-added service to technopreneurs worldwide. The Exchange provides a way of getting businesses moving forward through an effective method whereby, similar to their Trade Matching services, company leads are posted on the Exchange bulletin board and are simultaneously cross-posted to other 
technology-related bodies throughout the world.

\subsection{T4TECHonline}

This portal was recently developed by a spin-off company, T4Tech, with the support and sponsorship of ESA (T4TECHonline). The mission of T4Techonline is to support, via the Internet, the implementation of new technologies and know-how through the active involvement of a group of experts, covering all major technological and scientific sectors. The main objective is to fill the gap between technologies and the industrial needs of users through highly qualified technical consultancy. To provide a high quality service, T4Tech has signed several collaboration agreements with universities and research centres covering all the main technological sectors. Through these partnerships, T4Tech guarantees visibility, through the Web site, to the products, technologies and know-how that the research organizations are willing to provide.

Based on the experience gained within the first few months of activities, T4Tech has conceived the idea of developing a network of Web portals, whose main node will be T4Techonline. The idea is to simplify the search for consultancy or for technologies that fit the industrial needs of users by customising ad hoc Web environments according to each sector of interest. This network of intelligence, consistincy of different Web-portals (namely textile-t4tech.com, auto-t4tech.com and transportation-t4tech.com), will effectively favour the efficiency and success of the ESA TTP, due to the fact that the service is tailor-made for the customer's sector of interest.

\subsection{Technology bank}

The Technology Bank, operated by JRA Technology, contains information on a number of advanced technologies, developed by companies, universities and research organizations across a broad range of technology areas, that are currently available for licence and/or collaborative development by commercial organizations (Technology Bank). It includes technologies that have been developed by European space companies and that are available for transfer as part of the ESA TTP.

The aim of the Technology Bank is to focus on the most innovative technology and to provide industry with quick and easy access to information on it. In common with other technology exchange Web sites, the current listing of available technologies can be viewed and searched. The Technology Bank also contains requests for technologies that are being actively sought by JRA Technology client companies. Again, the current listing of technology needs can be accessed on the Web site. Organizations having a specific requirement for a technology, for example for a new product or to solve a manufacturing problem, are able to complete a Technology Requirements Form online.

Technology bank is a listing of technologies that are actively being sought by companies for new products, to solve technical problems they may have, etc. Entries are not attributed in order to prevent companies being inundated by enquiries from organizations who believe they have developed a solution to the requirement. This forces the enquirer to establish the contact through JRA Technology. This model is also adopted by many other similar technology transfer Web sites.

\subsection{Technology exchange}

The Technology Exchange Web site has an almost unique collection of business and technology opportunities - currently there are more than 40000 opportunities from some 92 countries available in its portfolio (Technology Exchange). For the past 15 years, 
Technology Exchange has helped more than 15000 organizations in more than 90 countries find the business partner they needed to succeed. The business introductions made by the Technology Exchange between donors and recipients of technologies, and technology-based opportunities have led to numerous licence, joint venture, turnkey, technical assistance, equipment supply, investment and distribution agreements.

The Technology Exchange, a not-for-profit organization, has set-up its Web site with UK government funding to bring this service to a wider audience and to utilize the technology available to deliver the information more efficiently and effectively. The site has current details of opportunities offered and sought and will, in the future, become a resource for all companies interested in technology transfer, with links to organizations, articles of interest and a 'members only' area with value-added information.

\subsection{Technology Mall}

The Technology Mall serves customers primarily, but not exclusively, in the manufacturing industry who are seeking innovations in various technology areas. The site offers a virtual forum which provides access to market-relevant innovations of the technology world. It serves as Internet marketplace where leading research and technology organizations, universities and high-technology companies that are looking for new ways to commercialize their innovations may showcase their developments, products, services and expertise globally to potential partners (Promotech 2001). The Technology Mall was established to offer a new and efficient channel for international technology marketing and technology transfer. A new site under construction will be available to anyone who wishes to present or learn about current high-quality research results that are ready for commercialization and that may have a critical impact on a company's competitiveness.

\subsection{United States Department of Agriculture (USDA) office of technology transfer}

The US Department of Agriculture (USDA) provides a Web-based gateway to new technological developments and services. Through its Office of Technology Transfer, businesses can stay abreast of a vast technology portfolio from USDA and Agricultural Research Service laboratories. The gateway gives access to a nationwide network of technical expertise and offers business opportunities in a host of areas ranging from biotechnology, precision farming and food production to the environment (United States of America, Department).

Businesses are able to leverage commercial productivity and increase markets through cooperative research and development agreements, access to an extensive patent portfolio and exclusive and non-exclusive licensing arrangements. In addition, the US Agricultural Research Service (ARS) works in conjunction with other USDA agencies to promote the transfer of new technology to the private sector and industry. These objectives are designed to create new businesses, improve industrial efficiency, increase employment, enhance US trade, preserve the environment and improve the quality of life of Americans.

The Web site gives licensing information, success stories of technologies in the marketplace and a searchable database of issued patents available for licensing. In addition, the TEKTRAN database provides summaries on the Internet of 'snapshots in time' - selected pre-publication notices - of recent research results from the Agricultural Research Service.

\subsection{Technology Transfer Information Center}

The Technology Transfer Information Center (TTIC) of the USDA's National Agricultural Library also helps to promote the rapid conversion of federally developed inventions into 
commercial products by getting the results of research into the hands of those individuals and organizations that can put it into practical use (United States of America, National). To accomplish these goals the Center provides a variety of services to professionals involved in the innovation process, including:

- working with an industry association to identify and prioritize research needs;

- hiring technology agents;

- writing and distributing thorough problem statements;

- canvassing federal laboratories and the university and private sector research systems to identify potential technologies to meet an industry's top priority needs;

- evaluating the technologies and documenting the findings in state-of-the-art reports; and

- disseminating reports to appropriate businesses.

\subsection{Virtual market place}

This innovative technology-orientated market place offers organizations the ability to search for technologies available for transfer, submit requests for technologies (not appearing in the market place), offer solutions to technical requests from other users and promote their technologies, services or know-how (Virtual Market Place). The aim of this site is to simplify access to advanced technologies and to facilitate the process of technology exchange.

The Virtual Market Place was developed by MST Aerospacy in Germany, which is the lead organization in the European network of technology brokers working in support of the ESA TTP. Using the Web site, users can find full details of the technologies within the ESA TTP portfolio - currently more than 200 technology descriptions including detailed background information and technical specifications, innovative aspects and potential application fields are available on the site. In addition, over 100 technological needs of companies are contained as well.

\subsection{Yet2.com}

Founded in 1999, yet2.com claims to be the first global forum for buying and selling technology on the Internet with already some 50000 major corporate users worldwide signed up (Yet2.com, 2002). A virtual technology marketplace, yet2.com offers companies and individuals the unprecedented opportunity to conveniently and privately purchase, sell, license and research some of the world's most valuable intellectual assets. Spanning all industries and areas of research and development, yet2.com is a community where technology officers, scientists and researchers can unearth cutting-edge discoveries as well as new applications for tried and true technologies. Yet2.com helps companies extract value from undervalued or unused technologies by streamlining the traditionally lengthy and ineffective process of technology transfer. The Web site allows users to find a technology, list a technology, and gain an insight into what is happening in the world of technology. Many of the world's premier research and development companies currently provide proprietary technologies on an exclusive basis to yet2.com, creating a robust marketplace where the world's most coveted inventions are listed, sold and, ultimately, applied.

\section{Conclusion}

The Internet clearly has an important role to play in assisting with the transfer of technology from a purely scienctific base. It offers a number of advantages over other mediums in terms 
of cost, the number of customers and/or end-users who can be targeted, the ease-of-update of information presented, and the rapidity with which enquiries can be made and responded to. World-Wide Web sites provide unique access to owners of advanced technologies who want to avoid costly research and development processes, increase speed-to-market, and maximize research and development profitability. In addition, such sites are marketplaces for licensable technologies from all over the world that facilitate non-intuitive connections between donors and receivers in areas which perhaps would never have been considered. Such sites are becoming increasingly sophisticated in terms of the presentation of information to users. It is now possible, for instance, to adapt the information users see in real-time as they navigate through a site. The advent of broadband will enable a plethora of new services which will be of direct relevance to Web-based technology transfer resources, e.g. video-conferencing and 'virtual' prototyping.

It is generally recognized that for many applications the Web is not really a revenuegenerating medium. Therefore a Web-based technology transfer resource is unlikely to be financially self-sustaining unless it is backed by a large portfolio, has a large user base and offers complementary services to assist users in writing technology descriptions and requirements, assessing their technologies, and receiving a commission for any introduction between parties and any subsequent deal.

Web resources established to promote technology transfer need to be constantly kept up to date to maintain user interest and need to continually promote their technology portfolios and services to ensure potential users are aware of their existence. Web sites set up for the purpose of technology transfer and exchange need to be designed in such a way that users can get rapid access to the information they are interested in. The sites should be backed-up by systems and infrastructure to ensure that all enquiries from users are handled quickly and efficiently. If the Web site is part of a technology company, it should complement the other technology transfer and marketing activities undertaken by the company rather than be the sole mechanism to promote and commercialize technology transfer opportunities.

However, organizations - be they commercial enterprises or academic institutions - which generate products or processes or ideas as a result of their research and development activities, will find that a technology transfer portal on the Web is an extremely valuable tool to assist potential users find and subsequently implement their knowledge.

\section{References}

DefenseTechLink. Welcome to Defense TechLink. [Online]. Available WWW: http://techlink.msu.montana.edu/dt/aero.html.

(Accessed 19 August 2002).

European Space Agency. 2002. Technology Transfer Programme. [Online]. Available WWW: http://www.esa.int/technology.

(Accessed 19 August 2002).

Promotech. 2001. Your partner for international business. [Online]. Available WWW: http://www.technologymall.com/.

(Assessed 19 August 2002).

Sibexlink Technology Exchange. G15 and Emerging South Portal. [Online]. Available WWW: http://www.sibexlink.com.my/techexchange/.

(Accessed 19 August 2002). 
T4TECHonline. The first European portal for consulting on new technologies. [Online]. Available WWW: http://www.t4techonline.com.

(Accessed 19 August 2002).

Technology Bank. Welcome to the Technology Bank. [Online]. Available WWW: http://www.tech-bank.com/. (Accessed 19 August 2002).

Technology Exchange. Together we mean business. [Online]. Available WWW: http://www.uktech.net/. (Accessed 19 August 2002).

Technology Transfer: intellectual and property rights. 2002. [Online]. Available WWW: http://oraWeb03.cern.ch:9000/pls/ttdatabase/display.main.

(Accessed 19 August 2002).

United States of America. Department of Agriculture. Office of Technology Transfer. [Online]. Available WWW: http://ott.ars.usda.gov/.

(Accessed 19 August 2002).

United States of America. National Agricultural Library. n.d. Technology Transfer Information Center. [Online]. Available WWW: http://www.nalusda.gov/ttic/. (Accessed 19 August 2002).

United States of America. NASA. n.d. Commercial Technology Network. [Online]. Available WWW: http://ctd.hq.nasa.gov/ (Accessed 19 August 2002).

Virtual Market Place. Welcome to Technology Forum. [Online]. Available WWW: http://www.technology-forum.com.

(Accessed 19 August 2002).

Wheeling Jesuit University. National Technology Transfer Center. [Online]. Available WWW: http://www.nttc.edu/. (Accessed 19 August 2002).

Yet2.com. 2002. Search and find the world's developed technologies for sale or license; or let them find you. [Online]. Available WWW: http://www.yet2.com/.

(Accessed 19 August 2002).

\section{Disclaimer}

Articles published in SAJIM are the opinions of the authors and do not necessarily reflect the opinion of the Editor, Board, Publisher, Webmaster or the Rand Afrikaans University. The user hereby waives any claim he/she/they may have or acquire against the publisher, its suppliers, licensees and sub licensees and indemnifies all said persons from any claims, lawsuits, proceedings, costs, special, incidental, consequential or indirect damages, including damages for loss of profits, loss of business or downtime arising out of or relating to the user's use of the Website. 
ISSN 1560-683X

Published by InterWord Communications for the Centre for Research in Web-based Applications, Rand Afrikaans University 